\title{
THE ANALYSIS OF MATHEMATICAL PROBLEMS USING NEWMAN STAGES REVIEWED FROM EMOTIONAL INTELLIGENCE
}

\author{
Yuli Nur Wahidah, Siti Inganah, Agung Deddiliawan Ismail \\ Study Program of Mathematics Education, Faculty of Teacher Training and Education \\ University of Muhammadiyah Malang \\ nuryuliw@gmail.com
}

\begin{abstract}
This study aims to describe student's mathematical problem solving abilities with high, medium, and low emotional intelligence. The type of this research is descriptive with qualitative-quantitative approach. Subjects in this study were students of Class VII of SMPN 3 Maron which amounted to 9 students. Data Obtained through questionnaires, tests, and interviews. Data analysis techniques used are Likert scale, average and percentage. The results showed the ability to solve mathematical problems based on the stages of Newman items, namely: students with high levels of emotional intelligence: (1) reading the problem, determining keywords, (2) understanding the problem, determining sufficient conditions, necessary terms and change the problem into the mathematical sentence, (3) the problem of transformation, determining relevant strategy, (4) process skills, executing strategy, (5) writing the answer, finding the answer and conclusion. Students with moderate emotional intelligence: (1) reading the problem, hesitating to determine keywords, (2) understanding the problem, being able to determine sufficient conditions and necessary conditions but cannot change the problem into mathematical sentences, (3) the problem of transformation, relevant strategies, (4) process skills, being able to execute the strategy but less accurate on the calculation process, (5) writing answers, answers and conclusions are less precise. Students with low emotional intelligence: (1) reading problems, not being able to determine keywords, (2) understanding the problem, being able to determine sufficient terms and conditions necessary but not yet able to change the problem into mathematical sentences, (3) transformation problem, less relevant, (4) process skills, many errors in the calculation process and did not complete until the final stage, (5) writing answers, have not found answers and conclusions.
\end{abstract}

Keywords: Problem Solving, Newman Stage, Emotional Intelligence

\section{INTRODUCTION}

The development of a country is determined by the quality of education. Mathematics is a field of study that has an important role in education. Fathani`s (2009) states that mathematics is important as a tool, as a science (scientists), as well as forming attitudes as well as guide mindset. This is because the math is often used to solve problems in everyday life such as economic and technological issues. Mathematics 
education in Indonesia is still low compared with other countries. This is indicated by the results of PISA (Program for International Student Assessment) in 2015 showed Indonesia was ranked 69 out of 76 countries. While the survey results Trends in International Mathematics and Science Study (TIMSS) were reissued by the Ministry of Education and Culture declared in 2011, Indonesia ranks 38th with a score of 386 from 42 countries. One factor that causes Indonesian students' mathematical ability is still low is because students in Indonesia are poorly trained in solving problems that require reasoning and creativity in solving the problem.

Based on the results of interviews conducted on 7 November 2016 at SMPN 3 Maron with one of math teacher the mathematical problem solving ability in form of about the story is still low. It can be seen from the results of daily tests that, most students still score below the KKM. Marsudi (2008) says that more than 50\% of teachers believed that most students experience an error in solving the story problems. The results of the interview also states, that most of the causes of errors in solving math problems is the lack of ability to understand the issues, the inability to interpret problems into mathematical form and lack of motivation in learning mathematics. The ability of mathematical problem solving is the ability of students to understand the problem, devise and implement solving a strategy (Aqib, 2013).

The ability to solve mathematical problems can be seen from student answer sheets. According to Newman (in White, 2010), students passed a series of stages to response to the problem including; reading problems, comprehending the problem, transforming of matter, processing skills , and write the answers (encoding). There are several factors affecting mathematical problem solving. Siswono (2008) mention four factors that affect the student's ability in problem solving, such as: early experience, mathematical background, structural problems, and motivation. The failure of someone to solve the problem and the absence of one's motivation becomes one of the causes of failure in managing the their emotions. Not all students have the same motivation. It resulted in the level of emotional intelligence of students vary.

Associated with research on the ability of mathematical problem solving to the level of emotional intelligence, Supriadi (2015) states that, students with high and medium emotional intelligence are able to do process of thinking problem solving well. While students with low emotional intelligence have difficulty in thinking process of 
problem solving. In line with this, Wulandari (2016) also states that students who have high ability and high emotional intelligence are capable to solve math problems correctly, students who have moderate ability with emotional intelligence level are less accurate in return score, students who have low ability with low level of emotional intelligence are less accurate in question.

\section{RESEARCH METHODS}

This research applies descriptive research with quantitative and qualitative approach that aims to describe in detail the mathematical problem-solving abilities from the data of the student answer sheets, interviews and the use of descriptive statistics including the average, the percentage of each stage by Newman stage. The subjects were students of VII grade SMPN 3 Maron in the second semester of the school year 2016/2017 who were selected based on the following procedure: (1) classifying students based on emotional intelligence of students, (2) choose three students both randomly based on the students emotional intelligence, and the consideration of teacher, (3) Selected research subjects in each group of emotional intelligence levels who will be assigned problem solving tesr and interviews.

Data collection techniques used in this study were questionnaires, tests and interviews. Questionnaire instrument is used to measure the level of emotional intelligence of students. The test instrument is used to measure the ability of mathematical problem solving based on the Newmn stage with two questions to amounting material. While the interview is used to analyze the results of the data collected of technical tests.

\section{RESULTS AND DISCUSSION}

Questionnaire scores data of emotional intelligence are obtained from the fulfillment of emotional intelligence questionnaire distributed to students of VII class C SMPN 3 Maron on March 6, 2017. The results are taken as a starting point to group students into three groups of students with a level of emotional intelligence high, medium, and low. Based on the results of the study, out of 27 students who obtained the highest scores on the emotional intelligence questionnaire is 90 and the lowest score is 71. The subjects used in mathematical problem solving test only 9 students consisting of three at each level of emotional intelligence. 
Data collection of mathematical problem solving test and interview is conducted on March 7, 2017. The data of mathematical problem solving were analysed by rubric on Newman which have been made and Interview results were used to get more in depth information. Discussion of the results of this study include the ability to read the problems (reading), to understand the problem (comprehending), the transformation of problem (transforming), processing skills (processskill), and write the answers (encoding).

a) Students with high level of emotional intelligence

Students with high level of emotional intelligence can solve mathematical problems very well. The results of this study are in line to Lestaringsih (2013) who states that students who have high emotional intelligence will be easier to solve mathematical problems. Based on this research, students with a high level of intelligence emosional in reading skills fall into the category of very high, since the student is able to determine the keywords that exist on the matter. The ability to understand the problems (comprehension) is categorized very high, since the students were able to determine with their own sentences about the sufficient conditions (things that are known) and the necessary condition (things that were asked) and were able to transform into a mathematical sentence.

The ability of transforming the problem (transformation) is classified very high, since the students were able to select the relevant strategies in solving the problem, for example being able to write the equation of things that are known from a mathematical problem. The ability to process (process skill) is categorized very high, since the students answer sheets are capable of running the planned method or strategy and each step of the calculations result the right answer. The ability of writing the answers (encoding) is classified very high, since the students are able to correct and interpret or infer a final answer in accordance with a given mathematical problem.

b) Students with medium level of emotional intelligence

The ability of mathematical problem solution of the students with medium level of emotional intelligence have some errors. Since they lack of precision in solving mathematical problems. The result of this study corresponds to Lestaringsih (2013) who states that students with medium emotional intelligence will result little disruption to 
solve problems that would affect in solving mathematical problems. The ability to read problems is qualified to the moderate category. Since students are still hesitant and confused in determining the keywords that exist in mathematical problems. The ability to understand the problems (comprehension) is qualified to moderate, since students are able to understand the problem well as seen from answer sheets and interviews, but they have not been able to exactly turn the story into a mathematics.

The ability to problem transforming is qualified very high, since students are able to choose methods, procedure or strategy that is relevant to find the desired answer. The ability to process skills (process skills) is qualified to very high, since the students answer sheets were able to execute the planned and in every step of the calculation resulted the right answer, yet they did not thoroughly do calculation process and strategy. The ability of writing the answers (encoding) is qualified to moderate. Since students are able to write the right answer, However, they did incorrect calculation process which resulted wrong conclusion.

c) Students with low level of emotional intelligence

The ability of solution mathematical problem of the students with low level of emotional intelligence is very poor. The result of this study corresponds to Supriya (2015) who says states that students with low emotional intelligence are poor in reading, understanding, transforming, process and writing the answer. Based on this study, the ability of reading problems is qualified to very low. Since the students are unable to determine the keywords contained in the mathematical problem.

The ability to understand the problems (comprehension) is qualified to very low category. Since the student can not write the sufficient conditions (things that are known) and the necessary condition (things that are asked) well. However, the interview shows that they are able to understand a mathematical problem by re-reading the test sheet problem solving and unable to change the question into the proper sentence of math. The ability of transforming problems (transformation) is qualified to moderate category, since the student are able to write method, procedure or strategy even thought they do not understand properly and less relevant stategies. This is because students do not master well the material, so that they use strategy carelessly.

The ability to process (process skill) is qualified to low category, since some student were not to determine relevant methods or strategies which affected to the 
calculation process and some other did not complete the final stage of the calculation process. The ability of writing the answers (encoding) is qualified to the low category. Since the students' answer sheets are still unable to write and find the correct answer. This happens, because the method or the strategy used is irrelevant, which affect is to the answers, likewise with the conclusions writing.

\section{CONCLUSION}

a) The ability of students with high level of emotional intelligence in solving mathematical problems is presented as follows. Reading problems, being able to determine the right keywords. Understanding the problem, being able to determine sufficient conditions, a necessary condition and able to turn a problem into a mathematical sentence appropriately. Transformation problems, being able to determine the relevant strategy. Process skills, being able to implement the strategy previously planned correctly. Writing answers, being able to find the answers and conclusions appropriately.

b) The ability of students with medium level of emotional intelligence in solving mathematical problems is presented as follows. Reading problems, students are still hesitant in defining keywords, understanding the problem, students are able to determine sufficient conditions and a necessary condition correctly but has not been able to turn a problem into a mathematical sentence. Transformation problems, being able to determine the relevant strategy. Process skills, being able to carry out a planned strategy before but less accurate in the calculation process. Writing answers, being able to find the answers and conclusions, but still lacking a precise

c) The ability of students with low level of emotional intelligence in solving mathematical problems is presented as follows . Reading problems, being unable to specify the keyword. Understanding the problem, being able to determine sufficient conditions and a necessary condition but not being able to turn a problem into a mathematical sentence. Problem transformation, in determining the strategy is still less relevant. Skills process, in implementing the strategy is still a lot of mistakes in the calculation process and do not carry out the calculation process until the final stage. Writing the answers, not being able to find the answers and the appropriate conclusions in accordance with math problems 


\section{REFERENCES}

Aqib, Z. 2013. Teaching and Research Models. Yogayakarta: Pustaka Pelajar.

Fathani, A.H. 2009. Mathematics of Nature \& Logic. Jakarta: Ar-Ruzz.

Lestaringsih, M. 2013. Profile of Student Ability in Solving Circumference Problem Based on Emotional Intelligence. STKIP PGRI Sidoarjo.

Marsudi, R. 2008. Learning Stories Relate to Addition and Reduction in Elementary School. Yogyakarta: P4TK.

Riduwan.2007. Formulas and Data in Statistics Analyzes. Bandung:Alfabeta

Siswono dkk. 2008. Mathematical Learning Model Based on Submission and Problem Solving To Improve Creative Thinking Ability. Surabaya: Unesa University Press.

Supriadi, D. 2015. Analysis of Student Thinking Process In Solving Mathematical Problem Based on Polya Step Judging From Emotional Intelligence Student Class Viii Smp Al Azhar Syifa Budi. Surakarta: Sebelas Maret University.

Wuladari, D.A. 2016. Profile of Mathematics Problem Solving for Junior High School Grade VIII Viewed from Level of Intelligence and Mathematical Ability. Surabaya: Unesa.

White, A.L. 2010. Numeracy, Literacy, and Newman's Error Analysis. Journal of Science and Mathematics. Education in Southeast Asia. 